\title{
INTRODUCTION
}

The main purpose of this investigation is to determine the cause(s) of solid solution strengthening effects in close-packed and body centered cubjc metal solid solutions. The understandIng of this phenomena has considerable technological importance from the viewpotnt of the design of materials for strength properties.

In 1956, dislocation pinning by solute atoms was widely accepted as the mechanism for solid solution strengthening in both fcc and bce metal soldd solutions (see for example, reference 1). The theoretical picture has been broadened considerabiy In the last decade; the mechanisms proposed to account for the phenomena can be grouped into the following categories:

1. Direct Effects of Solute Atoms
a) Dislocation pinning by solute atmospheres.
b) Solute atoms acting as random obstacles.
c) Geometrical effects (order strengthening).

2. Indirect Effects of Solute Atoms

Solute additions influence the strength indirectiy through the effects of solute additions on the dislocation density, the stacking fault energy, shear modulus and the difrusivity.

In the case of direct effects, solid solution strengthening will be observed; In the case of indirect effects, solute add tions can result in elther solid solution strengthening or solld solution weakening. A clear example of the latter phenomena has been polnted out in this research.2

\section{LEGA NOTICE}

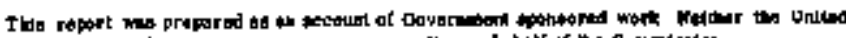

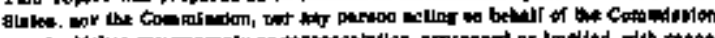

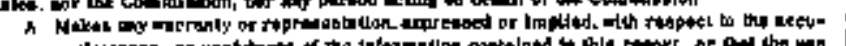

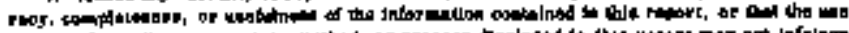

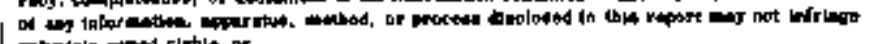

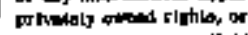

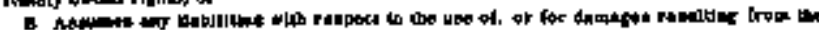

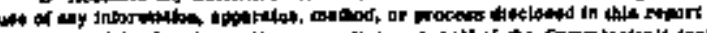

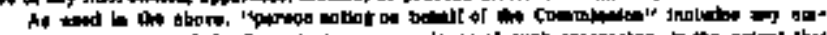

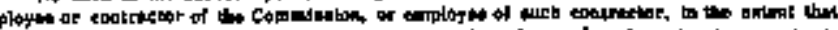

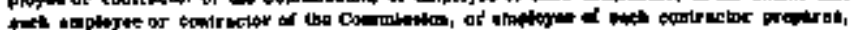




\section{DISCLAIMER}

This report was prepared as an account of work sponsored by an agency of the United States Government. Neither the United States Government nor any agency Thereot, nor any of their employees, makes any warranty, express or implied, or assumes any legal liability or responsibility for the accuracy, completeness, or usefulness of any information, apparatus, product, or process disclosed, or represents that its use would not infringe privately owned rights. Reference herein to any specific commercial product, process, or service by trade name, trademark, manufacturer, or otherwise does not necessarily constitute or imply its endorsement, recommendation, or favoring by the United States Government or any agency thereof. The views and opinions of authors expressed herein do not necessarlly state or reflect those of the United States Government or any agency thereof. 


\section{DISCLAIMER}

Portions of this document may be illegible in electronic image products. Images are produced from the best available original document. 


\section{Fcc Metal Soldd Solutions}

Our portion of this research concerns a detalled experimental study of the compositional and temperature dependence of the critlcal resolved shear stress, the activation energy and activation volume for deformation in dilute solutions of Ag-In and Ag-Sn allays. The objective of the research fs to evaluate the current theory of random obstacle strengthening. A preprint which describes the concentration dependence research is attached (Report Number c00-916-14); a research paper on thermally activated glide in dilute solutions of silver is currently in preparation.

Some of the 1mportant results of the above research area are given below:

1. The concentration dependence of strengthening depends on whether the solute addition is a "gradual" or "rapid" strengthener. Sn is a rapid hardener and obeys the $c^{t}$ relation.

2. The Pleischer ${ }^{3}$ size and modulus interaction parameter does not correctly predict the relative strengthening obtained on adding In and Sn to silver; the measured strengthening Imparted by $S n$ compared with In additions in infinitely dilute solutions, Is about 3 times that predicted by the theory of Fleischer.

3. The activation energies for deformation in Ag-In and Ag-Sn appear to be the same. The activation volume, however, Is considerably smaller for the Ag-Sn case. The greater temperature dependence of the CRSs for Ag-Sn alloys appears to be related malnly to this smaller activation volume. 
4. Measurements of the activation volume have disclosed empirical relations which should have considerable importance in the theory of thermaliy activated glide in fec solid solutions. The quantity $\frac{\partial \ell n v}{\partial \ell n c}$ is Independent of both temperature and composition and $\frac{\partial R_{n V}}{\partial \mathrm{nT}}$ is independent of both the solute species and solute concentration.

The secona research area in the fcc metal solid solutions concerns the measurement of dislocation velocities. The main objective here is to obtain a drect comparison of the stress dependence of dislocation veloesty with strain rate sensitivity. If solute strengthening is due only to a frictional resistance from solute atoms acting as random obstacles, then:

$$
\frac{\mathrm{d} \ln \overrightarrow{\mathrm{v}}}{\mathrm{d} \ln \mathrm{t}}=\frac{\mathrm{d} \ln \dot{\mathrm{E}}}{\mathrm{d} \ln \mathrm{t}}=\mathrm{m}
$$

where $\vec{v}$ is the dislocation velocity. On the other hand, if there is an important strengthening contribution from dislocation plnning, then there should be a marked difference between the strain rate sensitivity and the dislocation velocity exponent. The experimental work here is both tedlous and difficult; so far we have concentrated on experimental techniques such as crystal growth, crystal cutting, etc.

BCC Metal Solid Solutions

The research here concerns the strength and deformation quantities for $\mathrm{Cb}-\mathrm{Ta}$ and Cb-Mo solid solutions. Both the high $\left(\sim 300^{\circ} \mathrm{K}\right.$ ) and low temperature (to $4.2^{\circ} \mathrm{K}$ ) mechanical properties nave been invest1gated. Some of the lmportant observations in this work are g1ven below. 
1. The modulus interaction does not make an Important athermal strengthening contribution in $\mathrm{Cb}$ based alloys; solute hardening appears to be due to an atomic size interaction.

2. Thermally activated glide in $\mathrm{Cb}$ and $\mathrm{Cb}-\mathrm{Ta}$ alloys follows the Pelerls barrier model of Dorn and Rajnak. 4 In the case of Cb-Mo alloys, however, considerable deviation is found. It is possible that the large Ho atoms reduce lattice periodicity and the lattice frictional stress; themally activated glide in more concentrated solutions may be determined by short range Interactions between Mo atoms and gliding dislocations.

3. For testing at $4.2^{\circ} \mathrm{K}$ (in comoression), $\mathrm{Cb}, \mathrm{Cb}-\mathrm{Ta}$ and $\mathrm{Cb}$-Mo alloys show deformation twinning. In numerous cases, the stress required for twinning at $4.2^{\circ} \mathrm{K}$ was less than the flow stress at $77^{\circ} \mathrm{K}$; In addition, the strain rate sensitivity was either zero or negative where twinning predominated. Both of these results are predicted by the theory of Bolling and Richman." 
Solid Solutions of Silver

The research that concerns the perfection and concentration dependence of solution strengthening in dilute solutions of silver with indium and tin are descrfbed in the attached reprint (Research Document C00-916-12) and preprint (Research Document c00-916-14) and will not be repeated here. A continuation of this study of strengthening in dilute solutions of silver involves mainly the determination of the quantities required to describe thermally activated glide.

The investigation of the temperature dependence of the flow stress was extended to include tests at $4.20 \mathrm{~K}$. The results are given in Figure 1 as the increase in resolved shear stress on changing the testing temperatures from $300^{\circ}$ to $4.2^{\circ} \mathrm{K}$; the results of the temperature change tests for $300^{\circ}$ to $77^{\circ} \mathrm{K}$ are also included for comparison. Note that $\left(t 4.2^{-r} 300\right)$ is not appreciably laxger than $\left(\pi 77^{-1} 300\right)$ unt1l the solute concentrations exced about $0.5 \%$. Arother related phenomena concerns the depentence

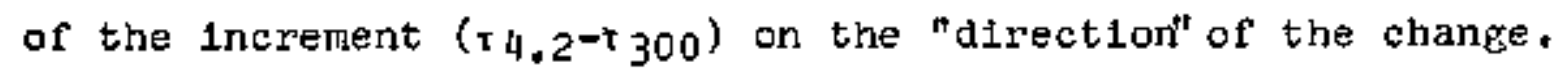
Table I below summarizes the data for silver-indium and silves-tin crystals.

\section{TABLE I}

$\left(\tau 4.2^{-\tau} 300\right) *$ for Stlver Solid Solutions

\begin{tabular}{|c|c|c|c|}
\hline Composition & & $\tau 4.2^{-\tau} 300\left(300^{\circ} \rightarrow 4.2^{\circ} \mathrm{K}\right)$ & $\tau 4.2^{-7} 300^{\left(4.2^{\circ}+300^{\circ} \mathrm{K}\right)}$ \\
\hline $\begin{array}{l}99.999 \% \mathrm{Ag} \\
0.038 \mathrm{At} . \mathrm{F} \\
0.215 \mathrm{\#} \\
0.440 " \\
1.690 "\end{array}$ & $\begin{array}{c}\text { In } \\
" \\
"\end{array}$ & $\begin{array}{l}22 \mathrm{gm} / \mathrm{mm}^{2} \\
36 \\
92 \\
140 \\
456\end{array}$ & $\begin{array}{l}-3 \mathrm{gm} / \mathrm{mm}^{2} \\
16 \\
66 \\
148 \\
467\end{array}$ \\
\hline $\begin{array}{l}0.027 \text { At. } \% \\
0.095 \\
0.728 \text { " }\end{array}$ & $\begin{array}{l}\text { Sn } \\
" \\
"\end{array}$ & $\begin{array}{r}70 \\
149 \\
498\end{array}$ & $\begin{array}{r}65 \\
158 \\
551\end{array}$ \\
\hline
\end{tabular}

* Corrected for the varlation of shear modulus w1th temperature. 
Note that a downward change in temperature produces a larger flow stress lncrease in the dilute solutions; in pure silver, an upward change yields a negative value, Basinskit has reported a reversible softening in silver crystals on cooling from $78^{\circ}$ to $4.2^{\circ} \mathrm{K}$ when tested 1 n the easy glide range. In more concentrated solutions, the upward increment becones somethat larger than the downward 1ncrement. It is apparent that the deformation structure at $300^{\circ} \mathrm{K}$ and $4.2^{\circ} \mathrm{K}$ are not the same; hence it is not possible to utilize the $4.2^{\circ} \mathrm{K}$ data in thermodynamic analysis of deformation. 7 The appearance of strongly serrated stressstrain curves at $4.2^{\circ} \mathrm{K}$ 1ndicate that twinning made important contributions to the deformation.

From $77^{\circ}$ to about $3400 \mathrm{~K}$, the temperature aependence of the CRSS values for Ag-In alloy crystals follow the $\tau^{\frac{1}{2}} \mathrm{vs}$. $T^{\frac{1}{2}}$ law. Th1s is show in Pig. 2 for indium contents ranging from 0.09 to 3 atomic In. Note that the values of Rogausch agree well with those in this investigation. One data point at $4.2^{0} \mathrm{~K}$ is included to show the break in the $\tau^{\frac{1}{2}}$ vs. $T^{\frac{2}{2}}$ relationship somewhere below $77^{\circ} \mathrm{K}$.

The activation volume for silver-indium alloys is given In Fig. 3 as a function of In concentration and the testing temperature. The values of $\mathrm{v}$ were measured through determination of fiow stress dependence of the strain rate in the easy glide range. Extrapolation of the $A g-I n$ data to 0,01 and 0,001 atomic does not give the values of $v$ for $99.99 \%$ and $99.999 \%$ Ag, resp.' This is not unexpected since the major impluities in silver do not Include indium. Note, however, that the relationsh1ps between 
$v$, Indium concentration (c) and temperature:

$$
\begin{aligned}
& \frac{\partial \ell n v}{\partial \chi n c}=K_{1}, \text { independent of both } c \text { and } T \\
& \frac{\partial \ell n v}{\partial R n T}=K_{2} \text {, independent of } c
\end{aligned}
$$

The data for $\mathrm{Ag}-\mathrm{Sn}$ (Fig. 4) complete only at $77^{\circ}$ and $300^{\circ} \mathrm{K}$ show that $K_{1}$ is smaller for the case of $t$ in additions; however, $\frac{d l_{n v}}{\partial \mathrm{ln}}$ is the same for both solutes. In addition, $K_{2}$ appears to have the same values in $\mathrm{Ag}-\mathrm{Al}{ }^{9}$ crystals and in $99.99 \%$ and 99.999\% AE. Note that the Friedel 11 prediction that $v=b^{3} / \mathrm{c}$ is not followed in elther case.

The activation energies can be calculated using the following relationship;

$$
\begin{aligned}
\Delta H & =-k T^{2}\left(\frac{\partial T}{\partial T}\right)_{\varepsilon}^{*}\left(\frac{\partial \ln \varepsilon}{\partial T}\right)_{T} \\
\text { or } \quad \Delta H & =T\left(\frac{\partial T}{\partial T}\right)_{\varepsilon}^{*} k T\left(\frac{\partial \ln \dot{\varepsilon}}{\partial \tau}\right)_{T}=T\left(\frac{\partial \tau}{\partial T}\right)_{\varepsilon}^{*} v \\
\text { since } \quad T^{\frac{1}{2}} & =A T^{\frac{3}{2}}+B \\
& \left(\frac{\partial \tau}{\partial T}\right)_{\varepsilon}=A \frac{\tau^{\frac{1}{2}}}{T^{\frac{1}{2}}}
\end{aligned}
$$

In addition, a correction must be made for the part of $\left(\frac{\partial \tau}{\partial T}\right) \dot{\varepsilon}$ that is due to the temperature variation of the shear modulus:

$$
\begin{gathered}
\tau=\tau_{g}+\tau^{*} \\
\left(\frac{\partial \tau}{\partial T}\right)_{t}^{*}=\left(\frac{\partial t}{\partial T}\right)_{t}-\frac{\partial \tau g}{\partial T}
\end{gathered}
$$

where $\left(\frac{\partial \tau}{\partial T}\right)_{\varepsilon}=A \frac{\tau}{T}$ and $\frac{\partial \tau g}{\partial T}=\frac{\tau g}{\mu} \frac{\partial \mu}{\partial T}$

Using the values of Neighbors and Alerg ${ }^{2}$ for $\mu$, the activation volume data and the data on the tenperature dependence of the CRSS, $\Delta$ H could be calculated over a range in compositions and temperatures. The results of these calculations for Ag-In alloys 
are shown in Figures 5 and $5 a$, at $\mathrm{T}_{\mathrm{e}}\left(\sim 340^{\circ} \mathrm{K}\right), \Delta \mathrm{H}=\Delta \mathrm{H}_{\mathrm{O}}$ since the contribution of the work done by the applied stress should now be negligible; $\Delta H_{0}$ should measure the interaction of an Indium atom with a dislocation in silver. As shown in Fig. 5, $\Delta \mathrm{H}$ (and $\Delta \mathrm{F}_{0}$ ) appear to be independent of concentration in the range measured. This, of course, would be expected if $\Delta \mathrm{H}_{\mathrm{O}}$ is the Interaction energy of In with a disiocation in silver.

Unfortunately, the data compilation for the Ag-Sn case is not complete. Prellminary calculations of $\Delta \mathrm{H}_{\mathrm{O}}$ indicate that the interaction energy of a tin atom with a dislocation in silver is about 1.3 times that for indium. This is an important result because the relative $\Delta H_{0}$ values for indium and $t$ in atoms are predicted rather well. In the Fledscher ${ }^{3}$ theory, the lotal of the size and modulus interactions is given by the following;

$$
\begin{aligned}
E=\Delta \mathrm{H}_{O} & =\frac{\mu b^{2} \times R^{3}}{3 \pi(1-v) r^{4}}\left|\varepsilon_{G}^{1}-{ }_{1} \varepsilon_{b}^{1}\right| \\
& =A \varepsilon_{\mathrm{g}}
\end{aligned}
$$

A calculation of $\varepsilon_{s}$ reveals that this quantity should be about 1.3 thmes greater for the Ag-Sn case, very good apreement with the ratio of the tentative experimental values for $\Delta \mathrm{H}_{0}$, On the other hand, we have previously pointed out that the rlejscher prediction of $T$ being proportional to $\varepsilon_{S}{ }^{3 / 2}$ is not in agreement with expertment, I 2

BcC Metal Solid Solutions

As has been previously reported, the only strengthening observed in $\mathrm{Cb}-\mathrm{Ta}$ alloys consists of indirect effects ${ }^{2}$ due to a change in shear modulus with composition. 
On the other hand, Mo additions to $\mathrm{Cb}$ result in considerable athermal strengthentag. This is shown in Figure 6 for crystals of random orientation; the Schmid factor was taken to be that for the most favorably oriented (110) [111] glide system.

From the variation in the lattice parameter of $\mathrm{Cb}$ with Ta additions, one would conclude that $\mathrm{Ta}$ and $\mathrm{Cb}$ atoms have the same size. Ta and $C b$ are also closely the same in properties such as corrosion resistance, electrochemical behavior, thermal properties, etc. However, they differ in one important respect; the shear modulus of $\mathrm{Ta}$ is nearly twice that of $\mathrm{Cb}$. According to Rudman, 13 the shear modulus for a Cb-Ta alloy is a linear combination of the shear modull for $\mathrm{Cb}$ and $\mathrm{Ta}$. Hence, there should be a solid solution strengthening contribution from the modulus interaction. Foliowing Fleischer: ${ }^{3}$

$$
\frac{d \tau}{d c}=\frac{G e_{s}^{\frac{3}{2}} c^{-\frac{1}{2}}}{1400}
$$

where $\quad$ s shear modulus

$$
\begin{aligned}
& \varepsilon_{g}=\left|\varepsilon_{G}^{t}-a \varepsilon_{b}^{\prime}\right| \\
& \varepsilon_{G}^{\prime}=\frac{I+\frac{\varepsilon_{G}}{2}}{\varepsilon_{G}}=\frac{1}{G} \frac{d G}{d C} \\
& \epsilon_{b}^{\prime}=\frac{1}{b} \frac{d t}{d C} \\
& b=\text { lattice parameter }
\end{aligned}
$$

and

a = Is a constant equal to three for sorew dislocations and sixteen for edge dislocations. 
For $\mathrm{Cb}-\mathrm{Ta}$ alloya:

$$
\begin{aligned}
\mathrm{db} / \mathrm{dc} & =0 \quad \mathrm{\varepsilon}_{\mathrm{b}}^{\dagger}=0 \\
\varepsilon_{\mathrm{G}} & =.75 \\
\varepsilon_{\mathrm{G}}^{+} & =.66 \\
\varepsilon_{\mathrm{s}} & =.66 \\
\frac{\mathrm{d \tau}}{\mathrm{dc}} & =1.52 \times 10^{3} \mathrm{~g} / \mathrm{mm}^{2} \mathrm{c}^{-\frac{1}{2}} \\
\frac{\mathrm{dr}}{\mathrm{dc}} & =\frac{1.52 \times 10^{3}}{(.05)^{3}}=6.78 \times 10^{3} \mathrm{~g} / \mathrm{mm}^{2}
\end{aligned}
$$

From reference 2 , it can be seen that $\frac{d \tau}{d c}$ as determined experimentaliy, 1s a factor of five less than that predicted by Fleischer. In addition, the additions of $\mathrm{Cb}$ to $\mathrm{Ta}$ cause a reduction in the CRSS; one would not expect this since Ta atoms should strengthen as repulsive rather than as attractive barriers. It appears, then, that the modulus interaction makes no contribution in Cb-Ta alloys; a very logical extension of this would be to conclude that the modulus interaction is not important in the solution strengthening of boc metals.

In contrast to the $\mathrm{Cb}-\mathrm{Ta}$ case, Pigure 6 shows that Mo additions to Cb make a large athermal strength contribution. Because no evidence for the modulus interaction was found for the $\mathrm{Cb}-\mathrm{Ta}$ case, we will now examine the size interaction.

Using the nomenclature of Fleischer, ${ }^{3}$ substitutional atoms In $\mathrm{Cb}$ will be classfried as gradual bardness. The distinction here is associated with symetry; single substitutional atoms are symmetric defects while interstitial atoms result in tetragonal distortions. According to Fleischer, a gradual hardener 
In $\mathrm{Cb}$ should give a hardening rate $\left(\frac{\mathrm{d} \tau}{\mathrm{dC}}\right)$ of about $G / 10 ;$ in the case of tho in $\mathrm{cb}$, the experimental value is $\mathrm{G} / 40$, order of magnitude agreement.

Figure 7 shows that the rate of alloy hardening in bcc metals correlates very well with size factor; the data of Figure 7 include both those of MitchelI and Raffo and of this investigation. The shape of Figure 7 is given as:

$$
\mathrm{d}\left(\frac{100}{\mathrm{~g}} \frac{\mathrm{d \tau}}{\mathrm{d} \mathrm{C}}\right) / \mathrm{d}\left(\frac{100}{\mathrm{~b}} \frac{\mathrm{db}}{\mathrm{dC}}\right)=0.5
$$

and $\frac{d \tau}{d c}=0.5 G E_{b}$ where $\varepsilon_{b}=\frac{1}{b} \cdot \frac{d b}{d C}$

The rate of hardening is found to be proportional to the misfit parameter to the first power. This is in contrast to those predicted by Fleischer, ${ }^{3}$ Mott,,$^{15}$ and Mott and Nabarro.16 Integration of $\frac{\mathrm{d} t}{\mathrm{~d}} \mathrm{y}$ yelds:

$$
\tau=0.5 \mathrm{G} \varepsilon_{\mathrm{b}} \mathrm{C}+\mathrm{A} \text {. }
$$

In Doc metals, a linear dependence of the room temperature strength 13 found in Ta-Re, ${ }^{14} \mathrm{Ta}-\mathrm{M} 0,{ }^{14} \mathrm{Te}-\mathrm{W},{ }^{19} \mathrm{Pe}-\mathrm{N} 1,{ }^{17} \mathrm{Fe}-\mathrm{Pt},{ }^{17}$ Fe-Cris as well as for the cb-Ho of this investigation. Hence, one is justifled in concluaing that the size factor is of first Importance in the high temperature solute strengthening of bcc metals.

Many 1nvestigations on the low temperature deformation of pure bcc metals have been carried out in recent years; most have concluded that the Peferls mechanism is rate controlling. $19,21,22,23,24$ 
One of the results of the theory of Dorn and Rajnak is that $\left(\mathrm{x}^{*} / \tau_{\mathrm{p}}^{\mathrm{o}}=\mathrm{f}\left(\mathrm{U}_{\mathrm{n}} / 2 \mathrm{U}_{\mathrm{k}}\right)\right.$; this is sald to be a universal feature of deformation in bec metals at low temperatures. In this relationship, $\tau * 1 s$ the effective stress, $\tau_{p}^{\circ}$ is the Pelerls stress, $U_{n}$ is the activation energy for the formation of a double kink and $U_{k}$ is the energy required to form a double kink at zero effective stress. A plot of $\tau^{*} / \tau^{\circ}$ vs. $U_{n} / 2 U_{k}$ should be the same for all materials whose deformation at low temperatures Is determined by the Peierls mechanism; verification of this has been obtained by Dorn and Rajnak, ${ }^{4}$ Lau et al., ${ }^{3}$ and Christian and Masters. I9 However, Evans and Flanagan 25 have pointed out that the relationship 13 characteristic of other thermally activated processes. Other experimental support for the Peierls mechantsm involves the independence of $\tau^{*}$ with regard to solute concentration and dislocation density; there Is a considerable body of evidence that there is no dependence of the strain rate or temperature dependence of the flow stress with the degree of cold work 19,23 or solute concentrations, 22,24,26, 27 Recent2y, however, Stein and Low ${ }^{28}$ on Fe and Stein 29 on Ho show that the flow is reduced at all temperatures investigated In the higher purity material. St1ll other parameters that are used to distingulsh between deformation mechanisms are the activation energy and activation volume. One would expect that these quantitites would be independent of purity and strain if the Pelerls mechan $1 \mathrm{sm}$ is rate controlitng.

In our investigations, both pure $\mathrm{Cb}$ and $\mathrm{Cb}-\mathrm{Ta}$ alloys appear to fit the requirements of the Feierls mechanism. The bases for this conclusion are as follows: 
1. A plot of $t^{*} / \tau_{p}^{a} v s . U_{n / 2 U_{k}}$ fits the prediction of the Dorn-Rajnak model.

2. The values of the activation volume for $\mathrm{Cb}$ and all Cb-Ta alloys vs, t* fall on the same curve.

3. The activation energies for deformation of $\mathrm{Cb}-\mathrm{Ta}$ alloys fall in band extending from pure $\mathrm{Cb}$ (lowest values) and pure Ta (hlghest values). Th1s would be as expected since the shear modulus of $\mathrm{Ta}$ is greatest. Apparently, the mechanical behavior of a Ta-Cb alloy can be described as that of a pure metal with the shear modilus of the alloy.

The case of Cb-Mo alloys is different. On adding Mo atoras, important changes in low temperature mechanical behavior occur. F1rst, Mo atoms extend strongly the upper temperature limit of thermally activated glide; this behavior has been found also in Ta-Re alloys.14 The activation volume (Figure 8 ) is increased considerably with the addition of 5 at. Mo; $v^{*}$ remains approximately constant with composition on exceeding about 5\% Mo. The activation energy for deformation is increased rapidly with Ho additions; this is shown in flgure 9 . It should be polnted out that the values of $\Delta H_{0}\left(\tau^{*}=0\right)$ in Figure 9 are underestimates for the cb-Mo alloy, especlally for the higher Mo contents, The reason for this is that $t$ * does not become zero for the more concentrated alloys until g rather high and stilil undetermined temperature. In Figure 9 , $\tau^{*}$ was taken to be zero at $371^{\circ} \mathrm{K}$; this is correct for pure cb but becomes more and more of an underestimate of the temperature for which $\tau^{*}=0$, 
as the Mo concentration increases. Even with the underestimate values of $A \mathrm{H}_{\mathrm{O}}$. the activation enthalpies increase much more strongly than they should on the basis of the Peierls mechanlsm; here, $4 H_{O}$ should vary the shear modulus ${ }^{4}$ of the alloy. At 20 atomic $\$$ Wo, the predicted value of $\Delta \mathrm{H}_{\mathrm{o}}$ would be $1.05 \mathrm{ev}$ compared with 0.75 ev for pure $C b$. It an be seen from Figure 9 that $A H_{0}$ is goout 1.5 ev at 20 oo which $1 \mathrm{~s}$ In serious alsagreement especially since the Figure 9 gives underestimates of $\Delta H_{0}$.

Even if thermally activated glide in pure $\mathrm{cb}$ is likely determined by the Eeleris mechanlsm, it is very possible that at some Mo concentration, impurity hardening becomes rate controli1ng. At larger concentrations of Mo, the Peferls barrier may be reduced considerably through the reduction in lattice periodicity caused by the misfitting solute atoms. The terperature dependences of the CRSS for both $\mathrm{Cb}$ and Cb-po alloys follow the $\tau_{1 / 2}$ vis. The relationship. If this relationship is extrapolated to zero ${ }^{\circ} \mathrm{K}$, then to 1 s obtained (recall that twinning 1ntervenes at $4,2^{\circ} \mathrm{K}$ so that we cannot use the experimental values). For Mo contents over 5 atomic $\%$, the $\tau \mathrm{Vs}, \mathrm{c}^{\frac{1}{2}}$ relation is followed Just as 1n the case of fcc solid solutions. This is indicative of an impurtty mechanism. In fact, 1t, would be puzzling if a strong hardener like Mo did not have a rather large effect on thermally activated gilde.

In the deformation (compression) at $4.2^{\circ} \mathrm{K}$, twinning was observed in alj cases. The occurrence of twinning was accompanied by the following phenomena: 
1. An audible nolse.

2. A simultaneous drop in load.

3. The appearance of the long, straight striations on the crystal surface which are characteristic of twinning.

The load drops were not large $\left(2250 \mathrm{gm} / \mathrm{mm}^{2}\right)$ and would probably not have been noticed without magnification of the load axis through zero suppresston.

If the twinning stress is taken to be the stress at the first noticeable load drop, then our results show that process of twinning in bco metals gives an inverted temperature dependence. In addition we have found the stra1n rate sensitivity to be zero or negative. This is in agreement with the theory of Bolling and Richman's (continual mechantcal twinnting). The CMP theory is based on the premise that propagation and not nucleation of a twin is rate controlling. For metals, the CHT theory yields the Inversions in the temperature and strain rate dependences of the flow stress in agreement with our findings. 


\section{PUBLICATIONS}

"Whe Effect of Purity on the Dislocation Density and Strength of Stlver Crystals," by R. H, Hammar, W. C. T. Yeh, T. G. Oakwood and A. A. Hendrickson. Trans. Met. Soc. AIME, 239, p. 1692 (1967). Reprints attached (c00-916-12).

"Sol1d Solution Strengthening in Dilute Solutions of Silver," by R. H. Hammar, R. A, Strahl and A. A. Hendrickson. Proceedings of the International Conference on the Strength of Metals and Alloys, Japan Institute of Metals (to be published). Preprints attached (c00-9.16-14).

\section{ORAL PRESENTATIONS}

"Solld Solution Strengthening in Dllute Solutions of Silver," presented by A. A, Hendrickson at the International Conference on the Strength of Metals and Alloys, Tokyo, September 1967 and at Hokkaldo University Seminar, Sapporo, Japan, September 1967. 
PERSONNEL

In addition to the principal investigator, the following graduate students have been engaged in research supported by this contract in the last year:

1. B. C. Peters will receive his Ph.D. defree in June 1968. His research in the boc metal solid solution has been supported under this contract for the past 4 years. Mr. Peters will very likely be awarded the first doctoral degree from Michigan Technological University since the reactivation of the doctoral program in 2962.

2. R. A. Strahl will complete his M.S, thesis requirements shortly. He 1s presently a research metallurgist at Dow Chemical Company, Rockj Flats, Colorado.

3. c. c. Chen's support under this contract began in September 1967; he is engaged in the dislocation velocity measurements, his doctoral thesis research area.

4. B. C. Young is conducting his M.S. thesis research in the araa of boc metal solid solutions. He will probably complete his degree in September 1968. 


\section{References:}

1. Dislocations and the Nechanical Properties of Crystals, John Wizey and sons, Nen York (1957).

2. B. C. Peters and A. A. Hendrickson, Acta Met. 2, 1121 (1966).

3. R. L. Fleischer, the Strengthening of iletals, D. Peckner, Editor, Reintiold Pubiishing Corp., London, p. 93.

4. J. E. Dorn and S. Rajnak, Trans, AIME, 230, 1052 (1964).

5. G. F. Bolling and R. R. Rlchman, Acta Het., 13, p. 709, p. 703, p. 745 (1965).

6. Z, S. Basinski, Ph11. 旧ag., 4, p. 393 (1959).

7. J. C. M. L1, Trans. AIME, 233, p. 219 (1965).

8. K. D. Rogausch (see P. Haasen, 2. Metallk., 55, p. 55 (1964).

9. A. A. Hendrickson and A. E. Fine, Trans. AIME, 221, p. 967 (1961).

10. W. C.'T. Yen, M. S. Thesis, Michigan Technological Univergity, 1965.

11. J. Frledel, Dislocations, Addison-lesley, Reading Mass. (1964).

12. R. A. Strahl and A. A. Hendrickson, Proceedings of the International Conference on the Strength of Metals and Alloys, JIfi (to be published).

13. P. S. Rudman, AIME Refractory Retals Conference, French Lick, Ind., (1965).

14. T. F. Mitchell and P. L. Raffo, Cand. J. Phys., 45, p. 1047 (1967).

15. N. F. Mott, Imperfections in Nearly Perfect Crystals, p. 173189, John Wiley and Sons, N. Y., (1952).

16. N. F, Mott and F. R. N. Nabarro, Strength of Solids, Physleal Soc. Lond,, 1948.

27. H. H. Kranzlein, H. S. Burton and G. V. Smith, Trans. AIME, 233, p. 64 (1965).

18. G. T. Horne, R. B. Ray and H. W. Paxton, J. Iron and Steel Inst., 201, p. 161 (1963).

19. J. W. Christian and B. C. Masters, Proc. Roy. Soe. Lond., 281A. p. 233 (1964). 
(2)

References: continued

20. J. R. Netghbours and G. A. Alers, Physical Revien, 111, p. 707 (1958).

21. H. Conrad, J. Iron and Steel Inst., 199, p. 364 (1961).

22. H. Conrad, Iron and Its Dilute Solid Solutions, Interscience (1963).

23. S. S. Lau, S. Ranj1, A. K. Mukhergee, G. Thomas and J. E. Dorn, Aeta ilet., 15, p. 237 (1967).

24. A. Lawley, J. Van den Sype and R. Maddin, J. Inst. Metals, 21, p. 23 (1962).

25. K. R. Evans and W. F. Flanagan, Trans. AI11 , 236, 1381 (1966).

26. H. Conrad and W. Hayes, ASY Trans., 56, p. 125 (1963).

27. H. Conrad and $W$. llayes, ASM Trans., 56, p. 249 (1963).

28. D. F. Stein and J. R. Low, Jr., Acta Met. 19, 1183 (1966).

29. D. F. Stein, Cand. Journal of Phys., 45, 1063 (1967). 



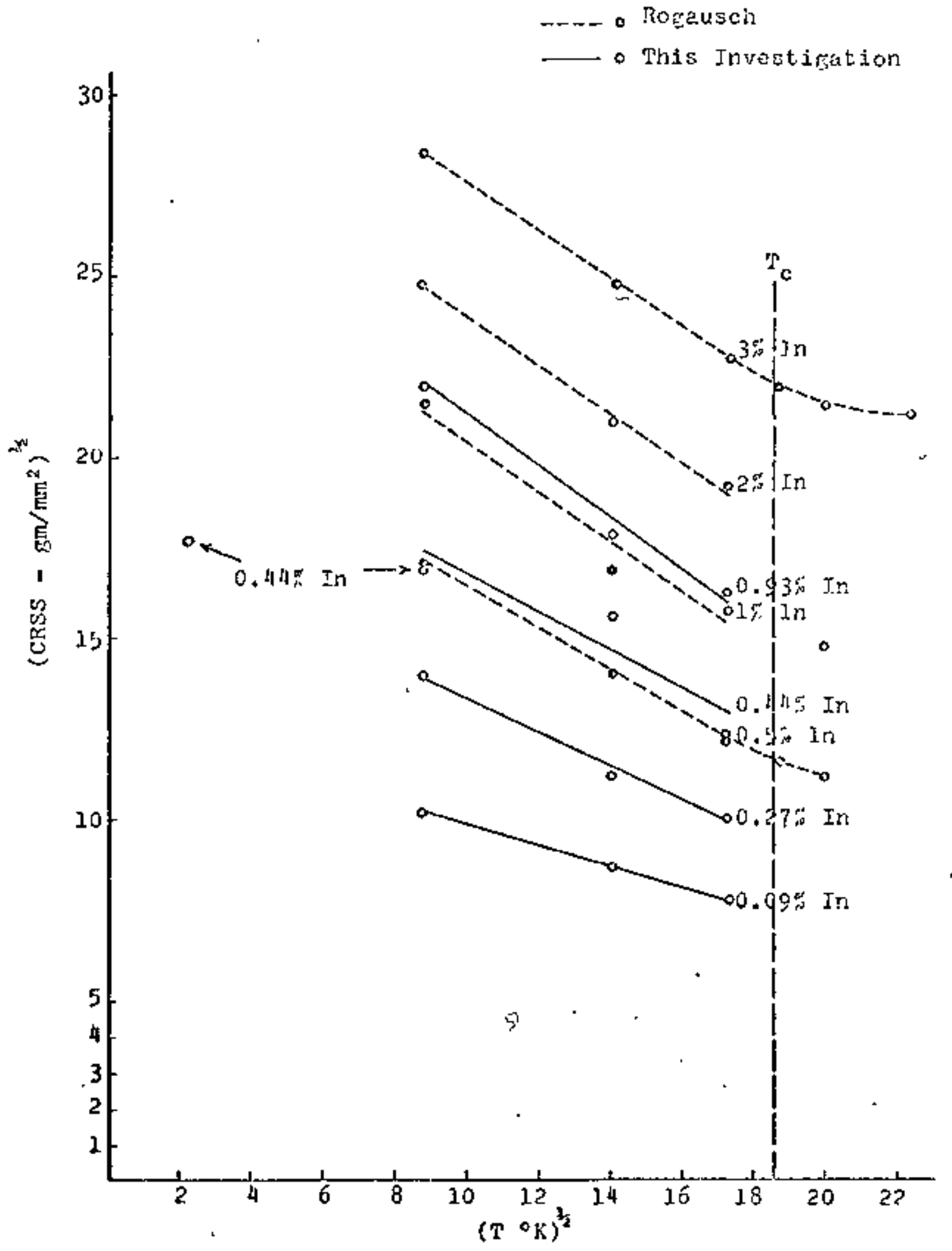

Pig. 2. T $T^{\frac{1}{2}}$ vs. $T^{\frac{1}{2}}$ for Ag-In Solld Solutions. 


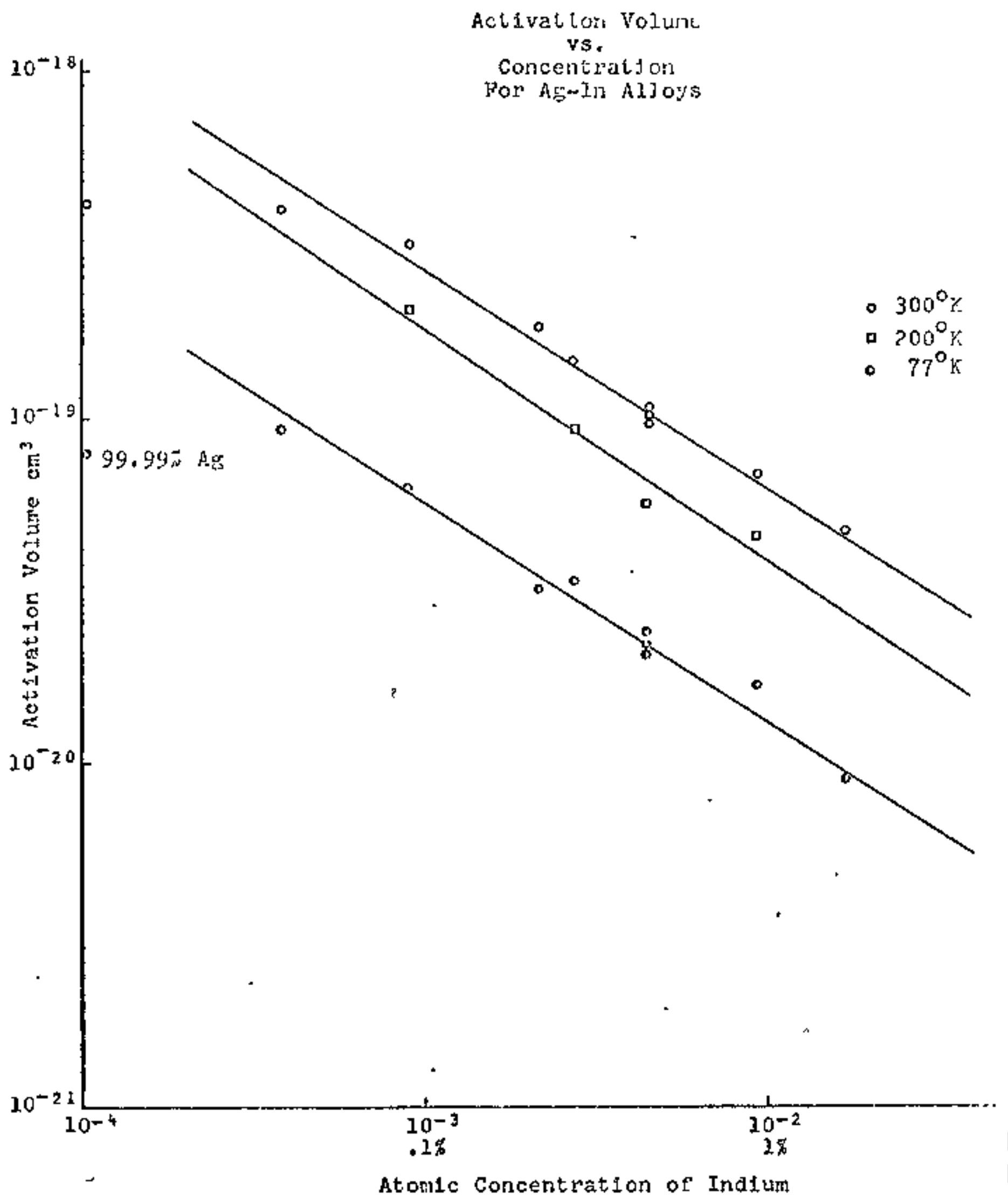

FIg. 3. Activation Volume vs. Concentration for Ag-In Solutions. 


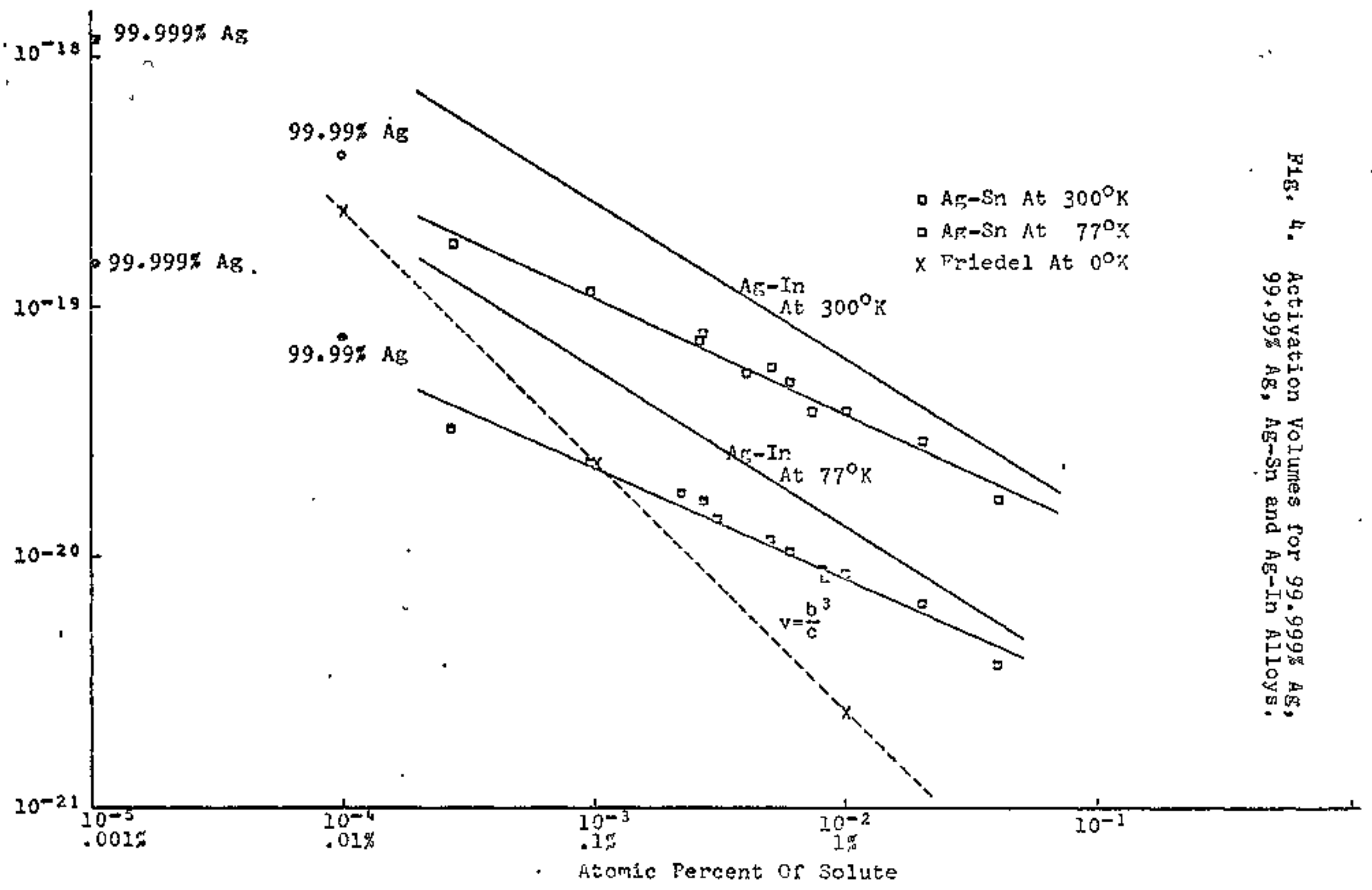




$$
\text { AS - In Alloys } \Delta E L \text { VS. T }
$$

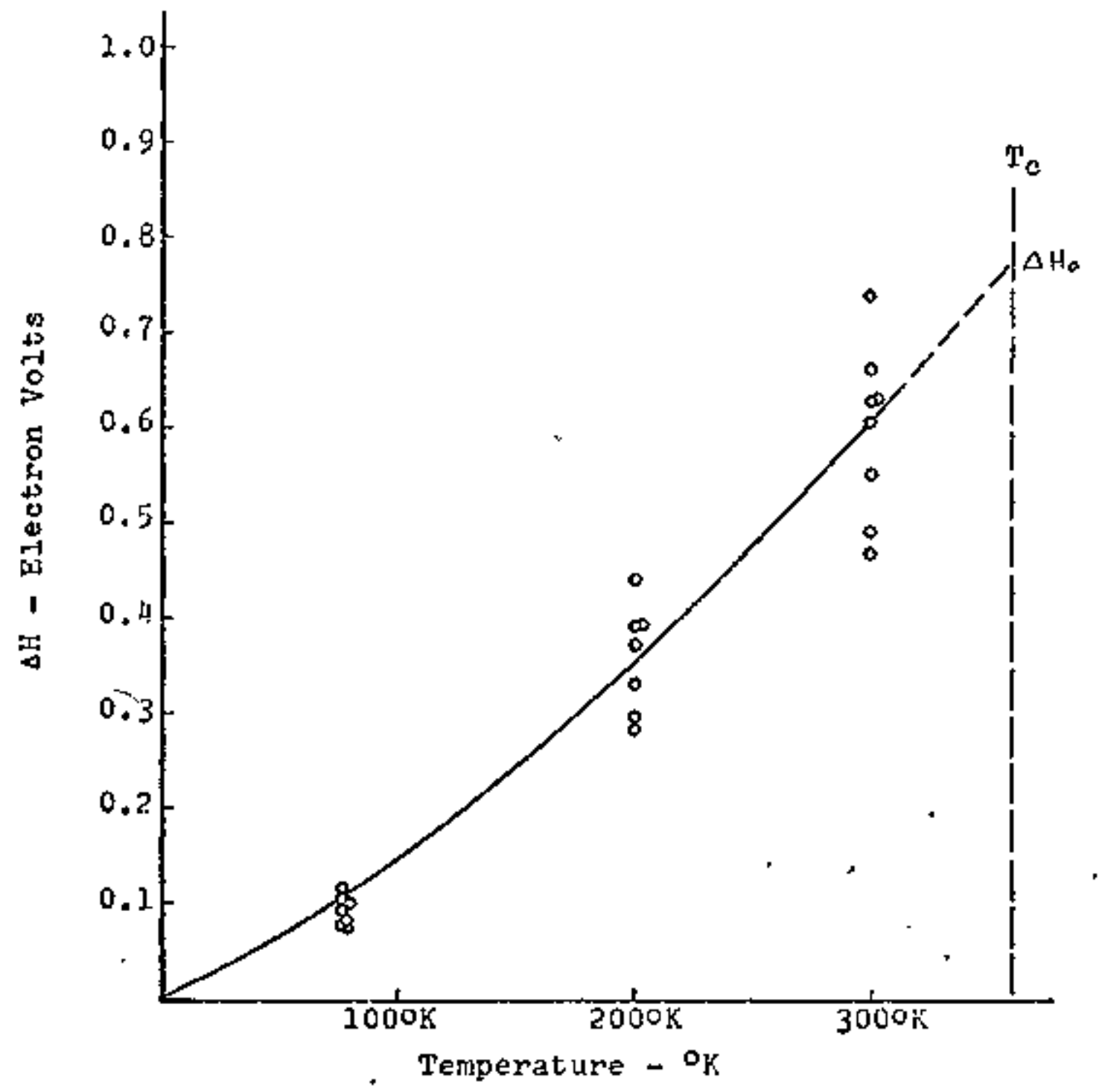

Fig. 5. The Activation Energy for Deformation of Ag-In Alloys as a Function of Temperature. 
Fig. Fa. The Activation Energy for the Deformation of Ag -In Alloys.
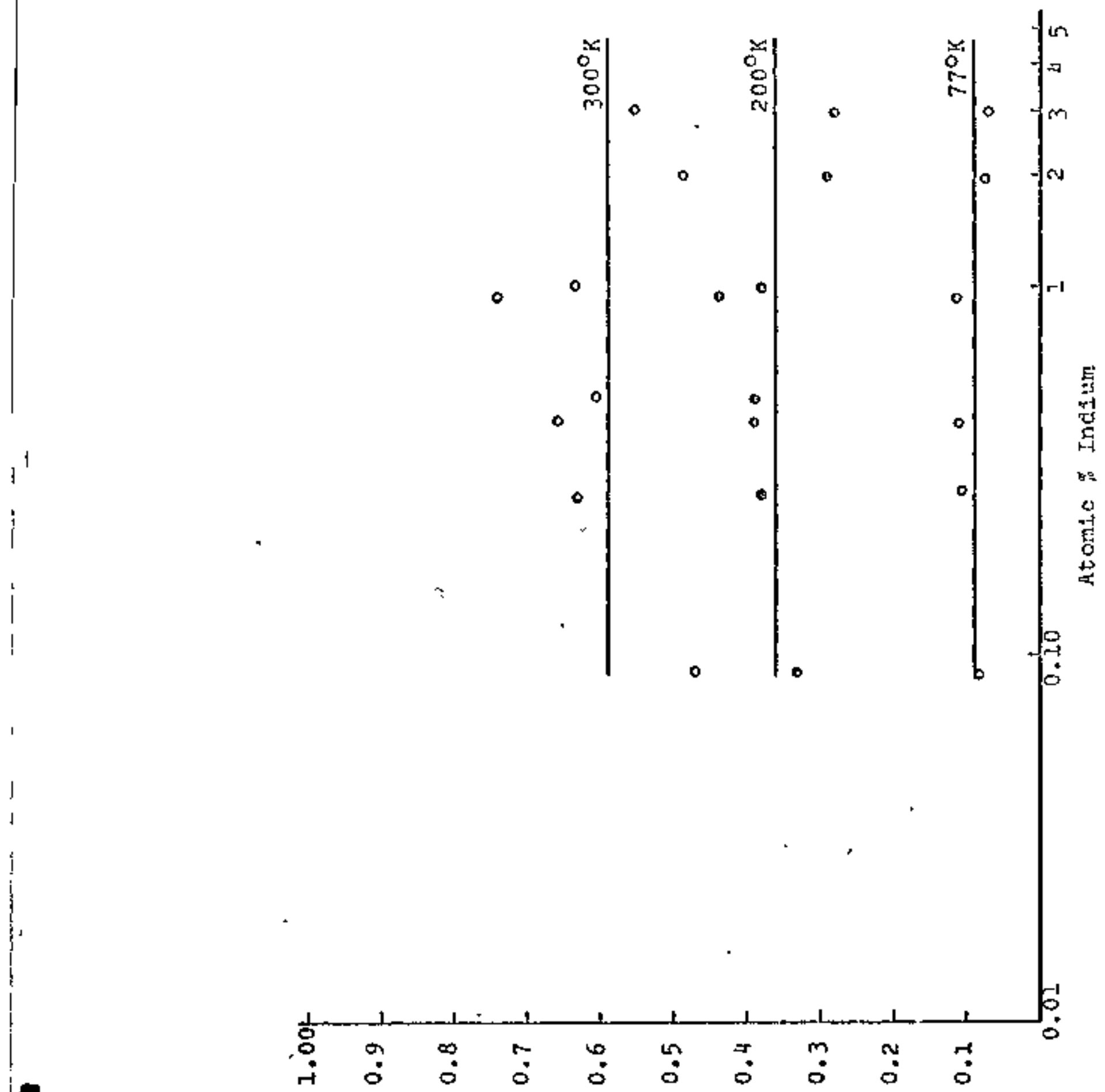

9710n 40.2759Tg - HV 


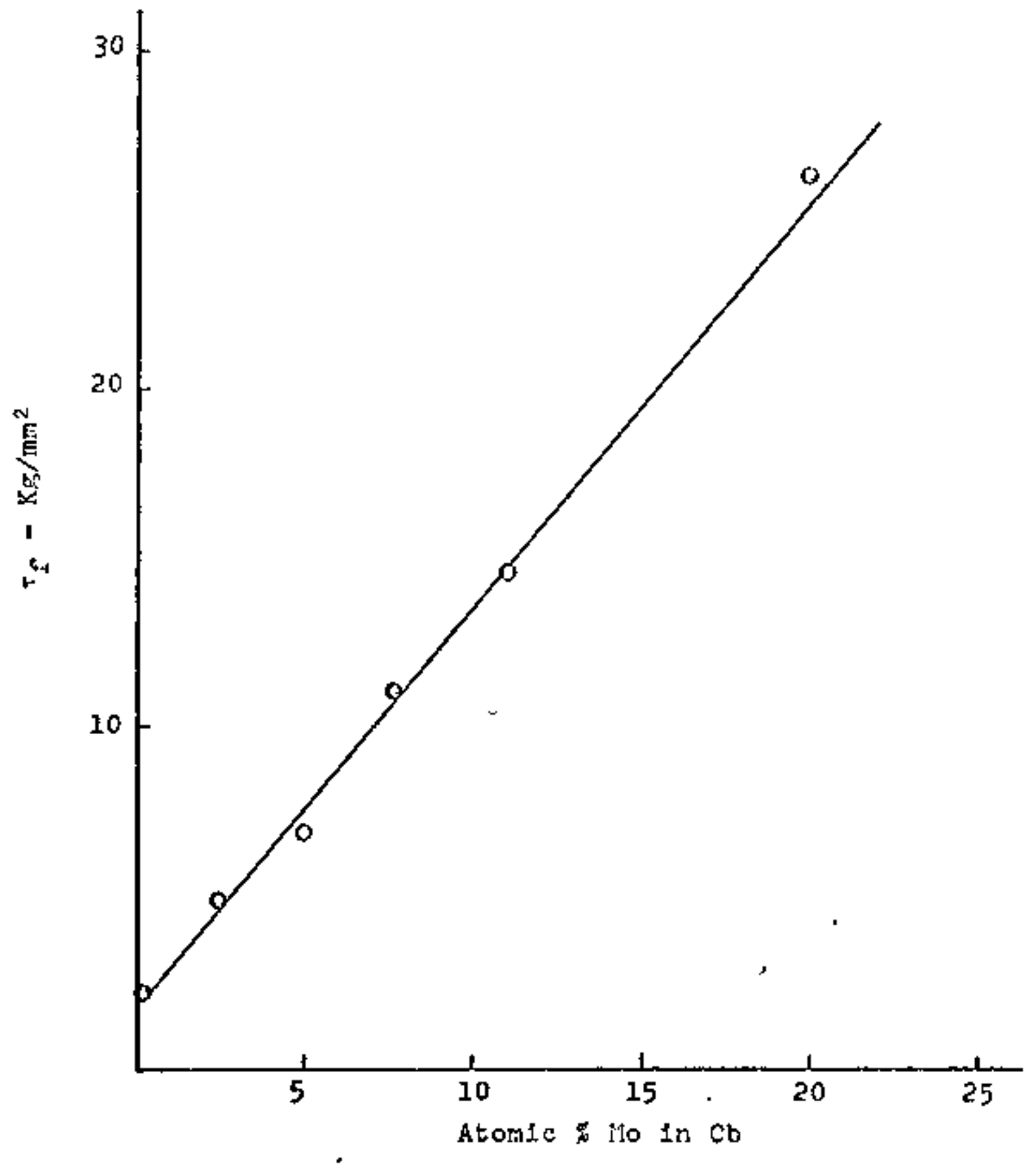

PIg. 6. The cRss of Cb-Mo Crystals. 


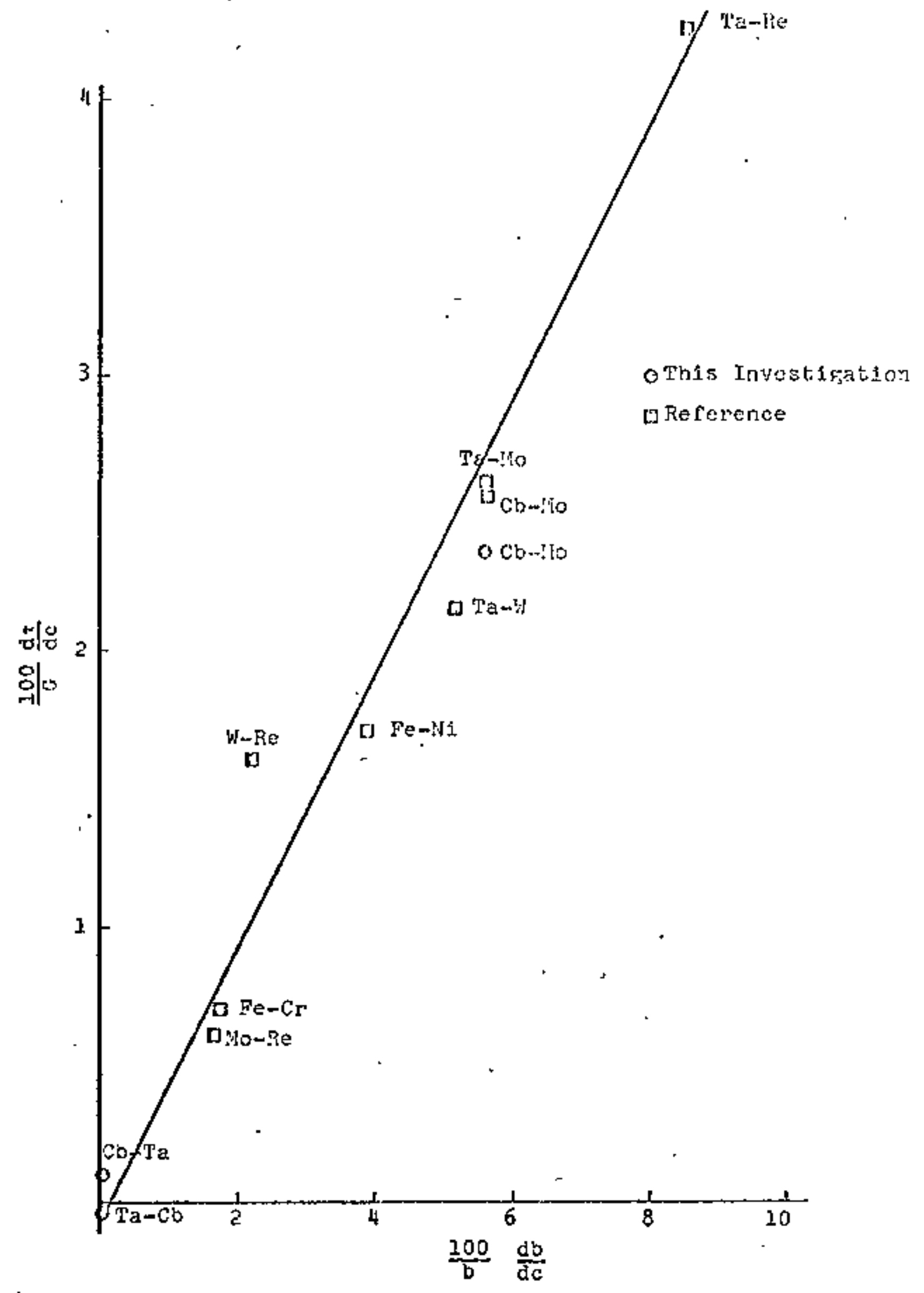

F1g. 7, Solid Solution Strengthening of BCC Metals vs, the Atomic Size Factor. 


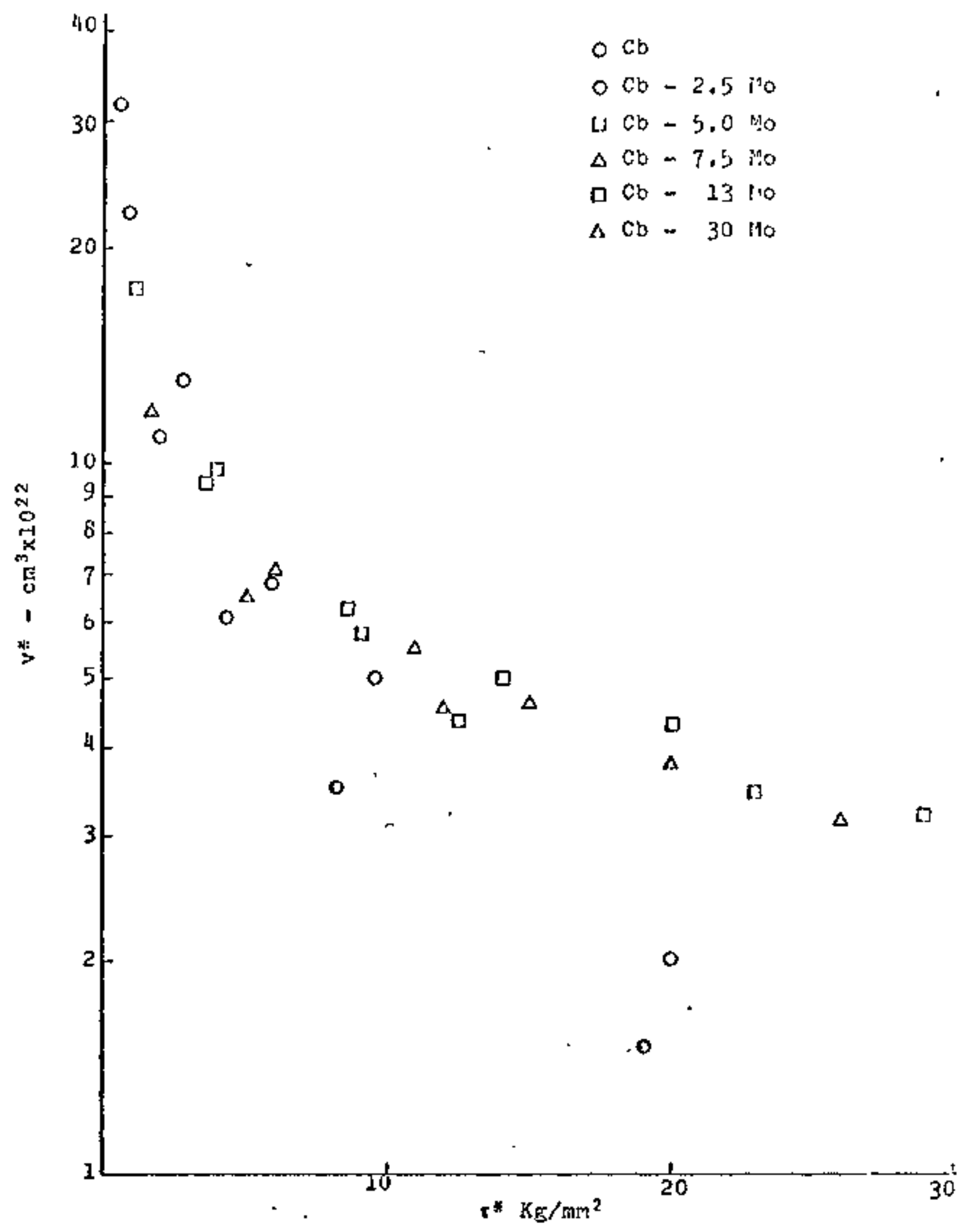

F1E. 8. Activation Volume vs, Effective Stress for $\mathrm{Cb}$ and Cb-Mo Alloys. 


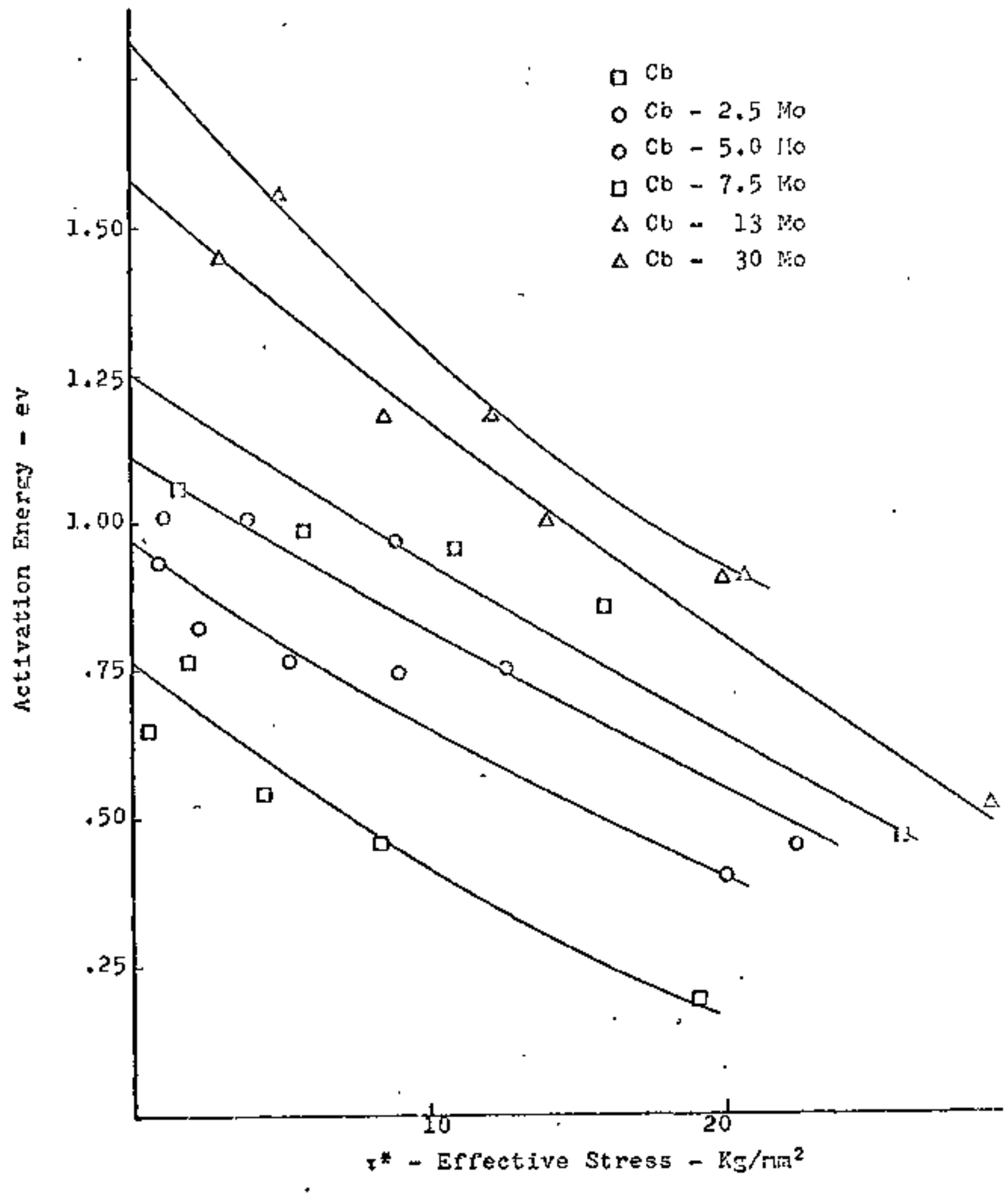

Fig. 9. Activation Energy for Deformation vs. Effective Stress for $\mathrm{Cb}$ and Cb-Mo Alloys. 